\title{
THE BOUNDARIES OF NATURE TOURISM
}

\author{
Gordon Waitt \\ Ruth Lane \\ Lesley Head \\ University of Wollongong, Australia
}

\begin{abstract}
This paper illustrates the malleable boundaries that define nature. Personal construct theory is employed to examine the apparent contradiction of the human/nature binary posed by landscapes generated by domesticated agriculture and physical and biological processes. Specifically, the paper reports on how tourists to the Kimberley region of Australia discriminate between their perception of human artifacts as attractions (including Lake Argyle, the Argyle Dam, and irrigated agriculture) and the region's gorges, rivers, billabongs, flora and fauna. Repertory grid analysis suggests that the Argyle Dam is perceived in a similar fashion to physical, geological, and biological attractions. However, the irrigated agriculture is perceived quite differently, as domesticated. Policy implications for the region's nature based tourism are explored. Keywords: personal construct theory, nature tourism, The Kimberley. (c) 2003 Elsevier Science Ltd. All rights reserved.
\end{abstract}

Résumé: Les lignes de démarcation du tourisme de la nature. Cet article illustre les frontières malléables qui définissent la «nature». On utilise la théorie de la construction personnelle pour examiner l'apparente contradiction du système binaire humain/nature, qui est représenté par des paysages générés par l'agriculture et les processus physiques et biologiques domestiqués. En particulier, l'article constitue un rapport sur la façon dont les touristes à la région du Kimberley, en Australie, font la distinction entre leur perception des attractions qui sont des constructions humanies (Lac Argyle, le barrage Argyle et l'agriculture irriguée) et celle des gorges, rivières, billabongs, flore et faune. Une analyse par grille de répertoire suggère que le barrage Argyle est perçu de la même façon que les attractions physiques, géologiques et biologiques. Par contre, l'agriculture irriguée est perçue comme apprivoisée. On examine les implications pour la politique du tourisme basé sur la nature de la région. Mots-clés: théorie de construction personnelle, tourisme de la nature, le Kimberley. C 2003 Elsevier Science Ltd. All rights reserved.

\section{INTRODUCTION}

This study attends to the way landscapes are constructed, circulated, and consumed in social space through various means of representation. In particular it provides an empirical case study of the relationship between promotional imagery texts and "the tourist gaze" (Urry

Lesley Head, Ruth Lane and Gordon Waitt are all currently at the School of Geosciences, University of Wollongong (Wollongong NSW, 2522, Australia. Email <gwaitt@uow.edu.au>). The Second author is a PhD candidate. Her thesis examines the spatial politics of land use change in the Kimberley. The other two are Associate Professors, both teaching in the School's Human Geography program. Their research interests include the social constructions of nature. 
1990). As Squire (1994) argues, landscapes become attractions through the meanings that are ascribed to them by promotional agencies and tourists. The purpose is to explore how marketing operates to naturalize human landscapes as "wilderness". In other words, how human artifacts are understood and experienced in such a way as to appear self-evidently true and unproblematic for nature-based tourism. The paper addresses the question posed by Selwyn (1996:29) whether the tourist is "a mere sucker for the surfaces of the tourism brochure". Drawing upon Dann's (1996) theoretical ideas that the promotional language not only guides but controls experiences, tourism marketing operates to sustain apparently contradictory structures within the Western culture/nature binary through a culturally derived system of signs and signifiers that either silences human impacts, making them invisible, or portrays them as natural.

The case study is an irrigation scheme, built during the 60s and early 70 s on the Ord River, in the East Kimberley region of Western Australia (Figure 1). The irrigation scheme includes Lake Argyle, Australia's largest artifact. This study investigates the role of various promotional imagery texts in sustaining the myth that the Kimberley is a "wilderness" location through tourists' own reading of the symbolism of promotional imagery. Its physical realities would appear to conflict with representations of pristine nature signified by the "last frontier" marketing pitch. Doing so, this paper involves a process that sustains "wilderness" in the public imagining of the East Kimberley, one of the founding colonial myths of white settlement of Australia (Langton 1994).

In examining tourists' consumption of promotional textual images, this paper develops a deeper understanding of how the tourism industry relates to the politics of land use in the East Kimberley. Presently the Kimberley is the focus of highly controversial debates about land use surrounding the irrigation proposal, Ord Stage Two. In the development context, potential for conflict arising from incompatible geographical imaginations of domesticated agriculture and frontier based nature tourism has so far been overlooked in consultants' reports concerned with social, economic, and environmental impacts (Hassall and Associates 1993; Kinhill 2000; Naralup Associates 1996). Within the context of the East Kimberley's contested politics of space, the potential implications of circulating colonial settlers' frontier myths in Tourism imagery texts are addressed. The promotional practices provide an avenue for determining how particular understandings of a place gain more authority than others do and may, in turn, inform land-use decision-making processes.

While sharing the aim of previous research in examining signs and shared meanings, this study differs from the majority of publications exploring the relationship between texts and tourist experiences in three ways. First, non-academic audiences were consulted for the interpretation of textual images, rather than solely relying upon hypothesized motivations and desires from a deconstruction of promotional images. The arguement goes well beyond the deductive approaches to text that dominate much current research (Markwick 2001; Waitt 


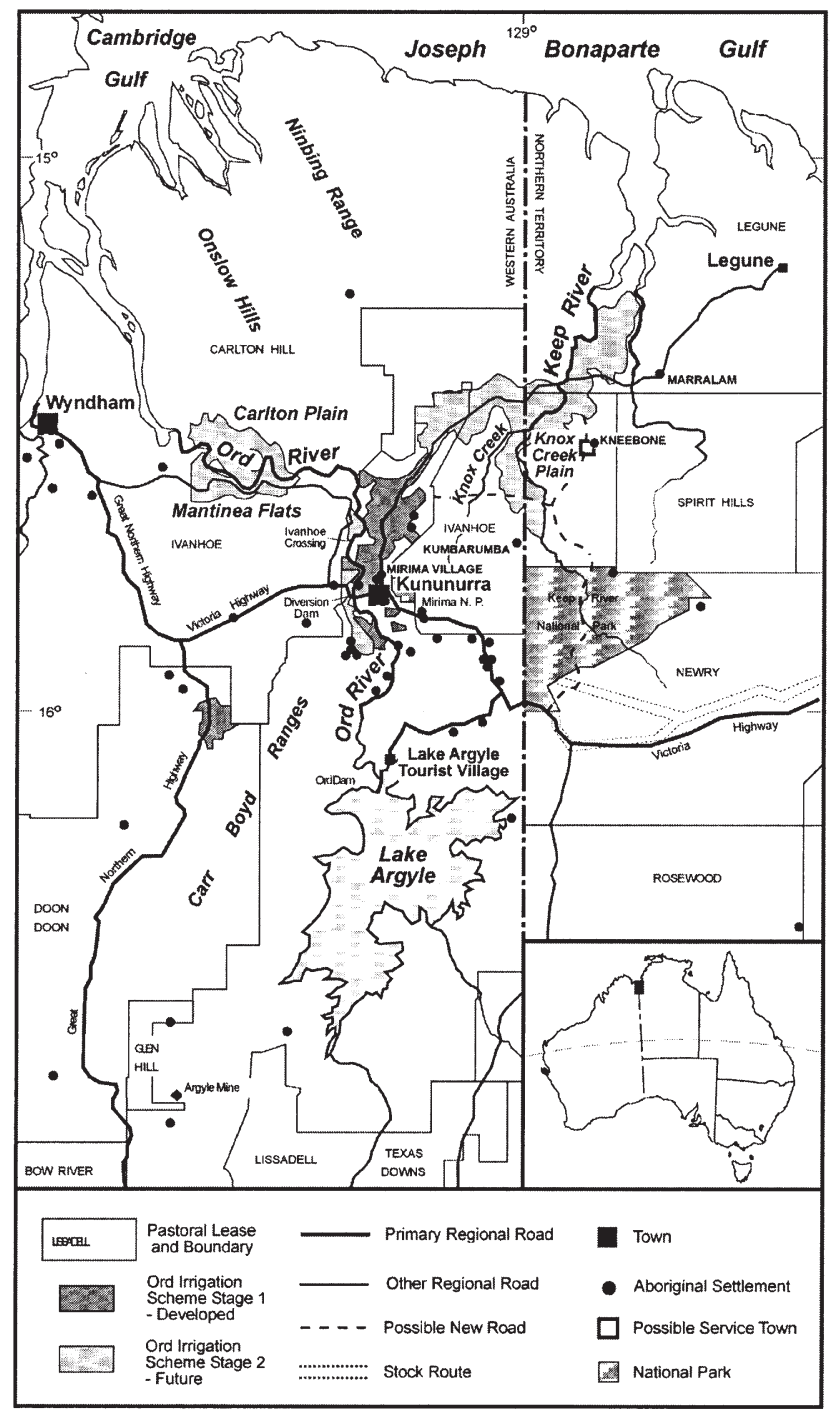

Figure 1. The East Kimberley Region

1997) and thus contributes to the growing interest in the reception and interpretation of texts and their influence on the society and culture to which the individual belongs (McGregor 2000).

Second, the epistemological positioning here is within critical realism (Sayer 1992) rather than social constructivism (Macnaghten and Urry 1995). The critical-realist position attempts to include the ontological assertions of empiricism as well as the epistemological concerns of constructivism: ideas are social concepts that have an ontological basis but are understood via a particular, socially predisposed 
framework. In other words, in this paper nature is not denied to exist as an object external to human experience. However, all knowledge is acknowledged as socially constructed and some abstractions can be extremely robust in terms of standing the test of time.

Third, an approach from psychology-personal construct theoryis drawn upon to examine empirically how tourists collectively experience attractions presented in promotional imagery texts. The psychological component of affective response has recently been ignored in the social construction of place in favor of more qualitative forms of analysis (for exceptions see Walmsley and Young 1998 and Young 1999). While adopting a quantitative approach, this should not be interpreted as a search for objectively based truth. Instead, personal construct theory is an empirical approach that enables identification of emotional meanings that people attach to environments, and thus complements qualitative analysis.

\section{TOURISM MARKETING AND TOURIST EXPERIENCES}

Elsewhere in the world, this scenery would attract thousands of tourists. But this is the remote Kimberley, so few even know of its existence (McGonigal 1990:7).

The Kimberley is a very recent tourism destination, located beyond the boundaries of established tourism circuits until the 70s. Travel restrictions included the semi-arid monsoonal climate with a nine-month dry season, temperatures in excess of 40 degrees centigrade as well as the absence of sealed roads, regular commercial flights, and accommodation. During the $70 \mathrm{~s}$, the primary focus was showing a specialistniche group, mostly middle aged Australian tourists, the failed cotton irrigation areas and dam infrastructure of the then newly built Ord River Irrigation Area (ORIA) (opened in 1972). Irrigation was made possible by the construction (at a cost of US $\$ 11$ million) of the Argyle Dam, the creation of Lake Argyle where the Ord River enters the CarrBoyd Ranges, and a diversion dam further downstream which raises the river level and diverts water for irrigation (Head 1999). The magnitude of Lake Argyle is represented in terms of either its capacity (5.5 million cubic meters) or that it is "nine times the volume of Sydney Harbor" (McGonigal 1990), enough "to supply the world's population with a thousand liters each" (Daly, Dehne, Leffman and Scott 1993:519). Yet, the dam wall is only $99 \mathrm{~m}$ high and $335 \mathrm{~m}$ long. At this time the irrigation area was made infamous, because two years after the opening, the area was abandoned due mainly to the prohibitive cost of pest control and the absence of viable alternatives to cotton. Furthermore, public controversy emerged with extensive media coverage over the dam's drowning of country (an estimated 2,000 square $\mathrm{km}$ in flood and the Western Australian Wildlife Authority's "rescue" endeavor, named "Operation Noah".

In the 80 s tourism benefited from the improved facilities and infrastructure associated with the irrigation scheme, such as the establish- 
ment of agricultural research stations and the building of Kununurra, ORIA's service and administrative center. In this decade too, the establishment of the Argyle Diamond Mine, later to become a tourism attraction in its own-right, also facilitated growth. Furthermore, agricultural output increased through the diversification into high return crops including cashews, peanuts, and chickpeas, as well as bananas and rockmelons. Backpackers, seeking casual employment during the fruit-picking season, began including Kununurra into their circuit.

At the same time, the appeal to independent and package tourists to northwestern Australia was increased, following the extensive publicity given to the "discovery" of the Bungle Bungles sandstone formations and with proliferation of air conditioned recreational 4 wheeldrive vehicles. Cited in guidebooks as "one of Australia's greatest natural attractions" (Daly et al 1995:564), the Bungle Bungles has market appeal to those motivated by adventure, nature, and/or eco-tourism. In part, this emphasis on the physical environment may account for the lack of an Aboriginal Australian presence in tourism, despite their numerically important presence within the Wyndham-East Kimberley Shire. Undoubtedly, also important were the negative experiences of Aboriginal people in relation to the formation and management of Mirima National Park (Senior 1987) and the Argyle Mine. Since the $80 \mathrm{~s}$, the "discovery" of the Bungle Bungles, the resurgence of ORIA, and the opening of the diamond mine, combined with a marketing emphasis shift to the environment, has seen tourist numbers substantially increase. Kununurra, for the majority of arrivals, is primarily a short stay service center from which to visit the Bungle Bungles, Lake Argyle, and the Argyle Diamond Mine. These attractions are often only part of a much larger self-drive through northwest Australia, with attractions often separated by thousands of kilometers.

Official figures reflect these trends. The Kimberley's tourist profile is mainly comprised of transient (average stay of three nights), independent tourists who often tour in off-road vehicles during the dry season of May to October (WATC 1996). Official figures suggest visitation numbers doubled between 1981/92-1994/1995, reaching around 108,000 arrivals in 1997. In the years to 2005, the estimated annual growth rate is 5\% (WATC and KDC 1998). Before the September 11 event in the United States, the percentage of overseas tourists was predicted to grow most rapidly, having doubled between 1995 and 1996 from 7 to $14 \%$ (WATG and KDC 1998).

\section{The Australian Frontier Myth}

The Kimberley, a mysterious, ancient land. So remote, so immense, so rugged-it challenges you to discover it ... the Last Frontier (a Slingair brochure).

The Kimberley is sold as the "last frontier". The Australian millionaire and adventurer-publisher Dick Smith confirms the legitimacy of this claim, asserting "that it would be hard to think of a place more worthy 
of the title of 'the last frontier' " (1990:3). The Kimberley trades on the fact that Australia's frontier has never been officially closed, unlike the American frontier which was declared closed in 1890 (Rose 1997a).

Closer examination of the tour brochures and guidebooks suggest the frontier marketing strategy has a hybrid character comprising sublime natural "beauty", the "real" Australia, "wilderness", and a setting for adventure and a proving ground for the young. As sublime natural "beauty", McGonigal comments that "the land and seascape that unfolded before us were awe-inspiring" (1990:7). The idea of the landscape as a source of marvel is reiterated by Moon and Moon: "Its [the Kimberley's] rugged ranges, wide sweeping plains and its jewel like sources of water $\ldots$ are a magical inspiration to us" (1997:17). As the "real" Australia, McGonigal claims that the Kimberley "epitomizes the image of Australia that Australians present to the world" (1990:11). The "real" Australia is a "timeless place" (WATC 1999:104), with "wide open spaces" (Moon and Moon 1989: backcover). The wilderness experience is epitomized by the latter authors' promise that "every person that visits ... will discover some secret spot" (1997:17). Further, as an adventure setting, the archetype of the Kimberley landscape is contained in the Australia Rough Guide's description of El Questro Gorge as "straight out of an Indiana Jones movie" (Daly et al 1995:520). Unquestionably, then, the Kimberley is marketed for its apparent timelessness, naturalness, and wilderness.

Marketing draws upon and perpetuates the 19th century European thought exploring human-environmental relations at the edges of nations, where human presence was believed to be absent. The frontier myth is called upon, and perpetuated by the contemporary tourism industry to sustain the portrayal of a pristine nature. Moreover, promotions suggest that the tourist cannot only visit an unknown and unusual place, but also move backwards in time. The Kimberley is presented as separated from the civilized world not only by space but also by a chasm in time, or what McClintock refers to as anachronistic space (1995:40).

Rose's (1997:27) concepts of "Ground Zero" and "Year Zero" help explore the marketing potential of the frontier myth. Ground Zero articulates the frontier's role in interpreting history by drawing upon the linear narrative of scientific progressivism, romantic primitivism, and polar binaries (savagery and civilization, wilderness and urban, wild and domesticated). A central tenet of the Ground Zero argument is that the advancing frontier has been the site of the formation of the both the nation and the national character. Historians Frederick Jackson Turner (1920) and Russell Ward (1958), respectively, articulated the frontier myth in America and Australia as a molding force of national character. Mary Durack's novel, Kings in Grass Castles, sustained and popularized that myth to many tourists, contending that those "frontier conditions ... have left a lasting impression on national character and governments" (1986:17-18). According to the environmental determinism of the frontier thesis it is argued that the so-called distinctive "Australian" attributes of independence, resourcefulness, mateship, and egalitarianism were in turn molded by the unique, 
inhospitable conditions of the Australian bush. A national character was constructed, born of the contest between nature and white, colonizing settlers.

As a white settler frontier, the Kimberley becomes a "marginal" location, outside the ambit of "human society". Instantly, according to the frontier myth, all marginal places become unpopulated landscapes, or at best peopled by "uncivilized" humans. The frontier myth draws upon the binary geographical imagination of "here" and "there" to erase indigenous peoples. A vast emptiness was essential for the frontier mythology, the place in which the new nation forms itself. Indigenous people were represented in frontier imagery as part of the environment and as destined to fade away as a natural consequence of their encounter with civilization. Settlers are represented as advancing "forward".

Within academe both these arguments of an Australian national identity born of the environment have generated strong criticism (Kapferer 1988; McGregor 1994). Equally, anthropologists suggest a far more complex picture of accommodation and resistance than the extinction proposed in the frontier thesis (Head 1994; Rose 1991). Despite such critiques, the Ground Zero myth still enjoys widespread currency within the tourism industry. The environmental determinism of the frontier still potentially operates to strip off the garments of civilization and array the tourist in a singlet and shorts, experiencing what the myth purports it means to be Australian. The Kimberley becomes the "real" Australia, understood as the antithesis of the urban, offering a place for personal self-discovery, regeneration, and renewal. Furthermore, a visit can be marketed as an escape to a wild place, free from the ills of contemporary society. The wild is an integral part of the frontier mythology, following the linear historical narrative of "civilization". It occupies a special niche in tourism place marketing because it is understood as a place without "us" (an escape), populated by indigenous people and creatures at once both wonderful and monstrous (the exotic). The wild remains unchallenged in tourism marketing, understood as that outside civilization's geographic and historical reach. By erasing the presence of indigenous people as human, and casting them as part of nature, the myth creates a vast emptiness in which tourists can become explorers and experience apparently pristine nature. The frontier as Ground Zero potentially offers tour operators not only a uniquely Australian product but also opportunities for escape, self-discovery, or heroism in a vast, pristine, wild, and reputedly empty natural environment.

Year Zero examines how the frontier thesis sustains an argument that places are separated by apparently occupying different temporal locations. By calling upon colonial discourses of primitivism and scientific progressivism, the frontier is culturally constructed as a disjunctive moment when both history and civilization are about to begin. The frontier is imagined as an ontological demarcation, cutting across country between timeless (prehistory) and historicized land. Rather than being an instance demarcated in time, the frontier is given qualities of liminal time because history is always about to begin, where 
something is about to happen, but has not yet quite begun. The Kimberley thus becomes portrayed as almost suspended in time. "Glacial time" is the term coined by Rojek and Urry (1997) referring to this apparent temporal hiatus given to portraying places at the margins of Western settler societies; this contrasts to the "instantaneous time" of cities. Year Zero gains currency within tourism, as it equips the industry with the illusion of time travel. A porthole to prehistory is opened to a place that time apparently forgot.

The frontier myth enables marketeers to flavor a journey with the romantic attraction of primitivism, tinged with allegedly distinctive qualities of Australian nationalism. While the tourism industry employs imagery and texts to sustain a particular mythical understanding, a multiplicity of receptions and interpretations are open to tourists. Acknowledging that they are not simply passive consumers, responding uncritically to a series of signs and symbols without regard for their personal attributes requires a methodology that can deal with these complexities. Personal construct theory addresses these difficulties by examining what each tourism attraction means for both the individual and tourists collectively.

\section{Study Methods}

Personal construct theory is employed in this study to explore the collective affective meanings of tourists responding to promotional imagery. Developed in clinical psychology by Kelly (1955), the theory assumes that people make sense of themselves and the world around them through formulating, testing, and revising hypotheses and developing theories. Personal construct theory, according to Warren (1990), claims knowledge about the world is not fact filled or given (accumulative fragmentalism), but is instead achieved through piecing together fragments of information (constructive alternativism). New experiences are interpreted using the order made out of previous ones as a basis. According to personal construct theory, individuals understand the world by erecting a complex, hierarchical, personally organized system of constructs (or interpretations) of experienced events. Although the system is personal, people can share or appreciate alternative interpretations. Hence, a construct is envisaged as a means for discriminating between objects, a mechanism by which to distinguish similarity from difference. However, a construct is not simply a verbal label. Each construct is an abstraction that subsumes some aspect of a repeated set of events of which the person is aware. Furthermore, Kelly (1955) envisaged constructs as dualistic. Equated to a line connecting two points (opposite poles), the construct's bipolar structure emphasized that affirmation and negation are integrally linked. Based on an individual's perception, an object can be placed somewhere on a scale between two poles, building a mental guide to the world. As a result of personal experiences (experimenting), constructs are constantly assessed. As such, personal constructs are envisaged as guidelines for living.

Repertory grid technique is the methodological component of this 
theory. Kelly devised it as a method for exploring personal construct systems. The grid enables the identification and the examination of relationships within a specific domain. The method has three main components: "elements" define the specific domain to be investigated, "constructs" are the ways that respondents differentiate between the elements, and "linking mechanisms" show how each element is judged on each construct. The value of repertory grids within various tourism domains has been recognized for over three decades (Pearce 1982; Young 1999; Zube, Pitt and Anderson 1975). In these and other applications, some minor methodological modifications have been necessary to extend its use beyond clinical psychology, where the original objective was to explore the roles that individuals play in interpersonal relations. For example, evaluation of landscapes by large numbers of respondents is frequently carried out using photographic surrogates rather than place or personal names. Nevertheless, the administration of repertory grid analysis generally proceeds in four stages: eliciting elements, eliciting constructs, completing grids, and analysis.

To ascertain how tourism marketing may help prevent discrimination between the ORIA artifacts and other attractions, "elements" had to be identified. In choosing elements, the advice of Fransella and Banniester (1977) and Easterby-Smith (1981) was followed: that elements should be specific, drawn from the same category or domain, representative and familiar to respondents. Therefore, an extensive review was conducted of the widely available and circulated promotional materials. This suggested that, given the aim of this project, several potential elements could be immediately eliminated, including those images of the Argyle Diamond Mine, Kununurra, and Wyndham. Of the remaining images, the promotional materials not only portrayed a limited number of "nature" based attractions but also utilized similar compositions, angles, time of day, and season.

From a "short list" of 90 promotional images, a representative sample of 13 was selected. In addition to the dam, lake, and irrigated agriculture, images included crocodiles, rock wallabies, bird-life, boab trees, a corroboree (an Aboriginal dance performance), a pastoral station muster, barramundi fishing, a billabong (lake), a waterfall with canyon, and The Bungle Bungles. Once the key elements were identified, constructs were derived from an initial survey of 40 respondents. Small sample sizes such as this one are typical in personal construct research; this is because of the method's time-consuming nature - upto one hour in many cases (Chokor 1991). Maximizing the sociodemographic diversity of respondents increased confidence in the elicited constructs. A quota-sampling frame was designed containing equal numbers of males/females, under/over 40s. In addition, to ensure that the experiences of tourists both familiar and unfamiliar with the attractions were incorporated into the constructs, the survey was conducted in two locations: the Kununurra shopping plaza during March 1999 and in Sydney (at Circular Quay and Bald Hill) during April 1999. Given that the object was to measure affective response to a particular attraction, it was not essential for a participant to have actually visited the attraction. In both locations, the sampling procedure involved sel- 
ecting the first eligible person to pass the interview points; that is, a tourist in a quota category that had not been exceeded.

To elicit constructs, respondents were presented promotional images within the standard triadic method (Fransella and Banniester 1977:14-19). This method involves presenting to the subject triads of elements with the questions "In what important way(s) are two alike and thereby different from the third?" Given time restriction and respondent fatigue, participants could not view each of the 286 possible triads with 13 elements. A pilot study indicated that an individual could consider 14 triads in around 20 minutes. By numbering each photograph and determining its selection with a table of random numbers, a random set of 14 triads was drawn subject only to the constraint that no attraction could occur more than four times. The random outcome was that six attractions occurred four times and six appeared three times. Therefore, subjects were presented with 14 random photographic elements, in triads.

Triads were presented in the same order to all subjects. A record was taken of the words used by respondents. Before viewing the first triad, subjects were reminded that they had to consider and differentiate among the photographs in terms of their own tourism and leisure experiences. In particular, they were asked to reflect upon how one attraction differed from the remaining two. Respondent appraisals are termed the "emergent" or "explicit" pole, and usually take the form of an adjective. To identify the "submerged" or implicit "pole", participants were asked to articulate what they considered to be the opposite of their description. In this way, each construct was recorded as a bipolar scale.

If each person in the combined surveys used a different construct to differentiate one element in the triad, the number of potential constructs would have been 576 . In fact, however, only 76 constructs were elicited because, predictably, some respondents provided similar adjectives. Not surprisingly, there was overlap between the feelings enunciated through words with similar meaning. Alternatively, even after questioning and probing, the elicited constructs remained situational (I have visited these sites), permeable (they are both animals), or vague (they are both okay). Furthermore, other subjects felt unable to construe a particular element.

Since 76 constructs are unmanageable within a questionnaire format, a smaller set of was derived from the elicited ones through a consultation process among the investigators. A smaller subset of 20 derived constructs was the outcome of a process in which the researchers independently and then collectively summarized the elicited constructs through word association. Each of the derived constructs then provided a mechanism for exploring how tourists discriminate between the ORIA and nature based attractions in terms of their affective response.

At the third stage, a second survey was conducted to examine the elements in terms of the 20 derived constructs. This was achieved using a repertory grid. A ratings technique was used to scale the gird, thereby uncovering the relationship between elements and constructs. For 
each element, respondents scored the 20 derived constructs on a six point bipolar scale, according to their perceived level of agreement or disagreement. No midpoint option was provided for participants. This decision was taken deliberately to eliminate the possibilities of respondents mistaking the middle of the scale as "not applicable", or "neither", or "both" scaled items. A pilot survey (5 respondents) suggested that to evaluate 13 attractions by 20 evaluative constructs would seriously overtax interviewees' patience. Therefore, each questionnaire included a random selection of only 10 images. The instrument also sought information on respondent tourism motivation (Pearce and Caltabiano 1983), holidaymaker classification (Yiannakis and Gibson 1992), tourism information sources, and sociodemographic backgrounds.

The second survey was conducted daily for a two-week period in May 1999, the beginning of the dry season, within Kununurra's backpacker accommodation, caravan, and camp-sites. These locations have two justifications. In practical terms, they provided shaded, cool, and comfortable venues in which tourists were relaxed and most willing to engage in completing a lengthy questionnaire, rather than in Kununurra or at attractions. Equally, these venues also provided sites from which to draw a representative sample from a constantly changing population.

Over 1,2000 tourists were invited to participate. A target sample of 400 completed the questionnaire, giving a response rate of less than $33 \%$. Once again the target sample contained equal numbers by gender and above and below 40 years of age. Constrained by the target quota's characteristics, the sampling procedure involved inviting eligible persons within these sites to participate in the survey. Refusal occurred for a variety of reasons including "not interested" (412, 34\%), "no time" (159, 13\%), "spoil vacation" (112, 9\%) and "have completed another survey" $(23,2 \%)$. Without any information about those who declined the invitation, it is not known whether the survey contains a nonresponse bias. However, from observations, older males, particularly those who voiced an intense scorn for academia and research are absent from this survey.

Of the 400 returned questionnaires, 338 were useable, 47 were incomplete, and 15 contained incorrect entries. The location and timing help to explain why those tourists who gave their consent to participate handled the substantial task of completing the survey without overt resistance or apparent respondent fatigue. The instruments were distributed through accommodation sites at "quiet" times, mainly between the hours of $3 \mathrm{pm}$ and $6 \mathrm{pm}$, when people were relaxing with nothing much else to do. Outside this period, tourists were too actively engaged in various pursuits or socializing to be concerned about filling in an extensive questionnaire.

Once a respondent has completed a repertory grid for a particular element, a matrix of scores can be calculated for each construct. In mathematical terms, each repertory grid forms a vector matrix that corresponds to the "cognitive set" of preferences for each participant. (Ward and Russel 1981). The cognitive set is the conceptual structure in a person's mind within which environmental stimuli are assessed. 
Each attraction is positioned within the rows and columns of the matrix defined by the respondent's evaluation of each construct's strength of presence or absence within their own cognitive set.

The repertory grid for an individual can be mathematically combined with those from other respondents to form an aggregated "supergrid" containing the mean scores or ratings for groups of people. Kalekin-Fishman and Walker (1996) provide a detailed argument for applying the principles of personal construct theory to individuals and groups with equal ease. Construction of the supergrid and its subsequent analyses was conducted using multidimensional scaling, which is somewhat similar to principal components analysis, specifically the replicated multidimensional unfolding solution available in the Statistical Package for the Social Sciences (SPSS). This technique examines the disparities among elements of the supergrid and uses them to create an n-dimensional space, which correspond to the aggregate personal constructs used to differentiate between environmental stimuli (Harrison and Sarre 1976). The first two bipolar dimensions, producing a two-dimensional space explained a high proportion of the variance in all grids. Using the loadings as coordinates, the elements were plotted in relationship to the two axes. This two-dimensional plot of point elements (attractions) corresponds to the cognitive set common to the subjects (Ward and Russel 1981). The configuration of this space is such that the distances among the point elements correspond to the disparities and similarities among the elements as recorded in the repertory supergrid. Labeling these dimensions is an extremely subjective process. Nevertheless, the loadings on the first dimensions suggest a pattern that might be labeled "domesticated-natural". Likewise, the second dimension seems appropriately described by the bipolar label "dangerous-safe".

\section{Study Results}

Characteristics of the sample are shown in Table 1. Age, gender and education evenly divide the sample, other than a slight under representation among persons in the 35-44 age cohort, due perhaps to the survey coinciding with the school-term. Respondents are primarily Australian, almost evenly distributed between Victoria $(49,14.5 \%)$, New South Wales $(47,16 \%)$ and Western Australia $(44,15.1 \%)$. International tourists came predominantly from Europe (99, 30\%), with two-thirds of these from the United Kingdom (63, 18.6\%). Occupationally, respondents are drawn from diverse socioeconomic circumstances (Table 1).

As shown in Table 2, respondents are united by their selfidentification as independent tourists; that is, they share a common desire to visit attractions but to make their own travel arrangements, often "playing it by ear". Tourists' major sources of information were from guidebooks, especially the Lonely Planet Guide (14\%). Learning from another person was also important. Among domestic tourists in particular, television was also a principal information source, especially 
Table 1. Respondents' Characteristics

\begin{tabular}{|c|c|c|c|c|c|c|c|}
\hline \multicolumn{8}{|c|}{ Respondent's Characteristics } \\
\hline \multirow{2}{*}{$\begin{array}{l}\text { Annual } \\
\text { Income } \\
\text { (US after tax) }\end{array}$} & \multirow{2}{*}{$\begin{array}{l}<8,000 \\
123 \\
(36 \%)\end{array}$} & \multirow{2}{*}{$\begin{array}{l}\mathbf{8 - 1 5 , 0 0 0} \\
62(18 \%)\end{array}$} & \multicolumn{2}{|l|}{$15-25,000$} & \multirow{2}{*}{$\begin{array}{l}\mathbf{2 5 - 3 5 , 0 0 0} \\
22(6 \%)\end{array}$} & \multirow{2}{*}{$\begin{array}{l}>\mathbf{3 5 , 0 0 0} \\
18(5 \%)\end{array}$} & \multirow{2}{*}{$\begin{array}{l}\text { Total } \\
293(87 \%)\end{array}$} \\
\hline & & & $68(20 \%)$ & & & & \\
\hline \multirow[t]{2}{*}{ Occupation } & Retired & Student & Unemployed & $\begin{array}{l}\text { Home } \\
\text { Duties }\end{array}$ & Blue Collar & $\begin{array}{l}\text { White } \\
\text { Collar }\end{array}$ & Total \\
\hline & $99(29 \%)$ & $23(7 \%)$ & $90(27 \%)$ & $26(8 \%)$ & $30(9 \%)$ & $67(20 \%)$ & $335(99 \%)$ \\
\hline Gender & & \multicolumn{2}{|l|}{ Male } & & $\begin{array}{l}\text { Female } \\
164(50 \%)\end{array}$ & & $\begin{array}{l}\text { Total } \\
338(100 \%)\end{array}$ \\
\hline \multicolumn{2}{|l|}{ Highest } & \multicolumn{3}{|c|}{ Primary/Secondary } & \multicolumn{2}{|l|}{ Tertiary } & Total \\
\hline \multicolumn{2}{|l|}{ Education } & \multicolumn{3}{|c|}{$161(47 \%)$} & \multicolumn{2}{|l|}{$164(49 \%)$} & $325(96 \%)$ \\
\hline \multicolumn{2}{|l|}{ Tourist } & \multicolumn{3}{|l|}{ Domestic } & \multicolumn{2}{|l|}{ International } & Total \\
\hline \multicolumn{2}{|l|}{ Market } & \multicolumn{3}{|l|}{$\begin{array}{l}\text { Total: } 203 \\
(60 \%)\end{array}$} & \multicolumn{2}{|l|}{$\begin{array}{l}\text { Total: } 135 \\
(40 \%)\end{array}$} & $338(100 \%)$ \\
\hline \multicolumn{2}{|l|}{$\begin{array}{l}\text { Age } \\
\text { (years) }\end{array}$} & \multicolumn{3}{|l|}{$\begin{array}{l}\mathbf{1 8 - 4 4} \\
169(50 \%)\end{array}$} & \multicolumn{2}{|l|}{$\begin{array}{l}\mathbf{4 5}->\mathbf{6 5} \\
160(47 \%)\end{array}$} & $\begin{array}{l}\text { Total } \\
329(97 \%)\end{array}$ \\
\hline
\end{tabular}

travel programs such as Getaway (8\%) and documentaries such as The Bushtucker Man, and The Malcolm Douglas Adventure Series.

Rank motivation scores shown in Table 2 confirm Pearce and Caltabiano's (1983) assertion that people have more than one travel objective. This table suggests the emergence of four intentions of almost equal importance: to develop relationships, to be stimulated, to relax, and to develop self-esteem. Statistical tests (Wilks Lamda) suggest that gender, age, and occupational differences in motivation were significant. Males, for example, were more motivated by the desire for adventure while females sought people's histories, particularly those of indigenous cultures, where F-value was found to equal 0.87 ( $d f=19$, $p=0.014)$. By age cohorts, a Bonferroni-Dunn post hoc test suggests the significance $(\mathrm{F}$ - value $=0.55, d f=95, p=0.001)$ can be attributed to three distinct categories of motivation. The youngest expressed the greatest desire to test their physical abilities. The middle-aged were more motivated by a desire to relax. Self-esteem and a desire to gain a sense of fulfillment motivated the elderly. By occupation, a Bonferroni-Dun post hoc test suggests that the statistical significance $(\mathrm{F}$ - value $=0.49, d f=114, p=0.001)$ is attributed to those employed in "white collar" occupations being most likely to express relaxation as a very important motivation. In contrast, student and unemployed occupational categories showed greater affinity with a sense of adventure and discovery. Their accomplishment is not a solo pursuit. The most important motivation was to develop relationship with friends, partners and others. Apparently, sharing the experiences with others is as important as the experience itself. 
Table 2. Tourist Characteristics

\begin{tabular}{|c|c|c|c|c|c|}
\hline \multicolumn{6}{|c|}{ Mean Motivation Scores ${ }^{a}$} \\
\hline \multirow[t]{4}{*}{ Highest } & \multicolumn{5}{|l|}{ Relationships 4.5} \\
\hline & \multicolumn{5}{|l|}{ Stimulation 4.4} \\
\hline & \multicolumn{5}{|l|}{ Relaxation 4.2} \\
\hline & \multicolumn{5}{|l|}{ Self-esteem 4.2} \\
\hline Lowest & \multicolumn{5}{|l|}{ Fulfillment 3.3} \\
\hline \multicolumn{6}{|c|}{ Ranked Holiday-maker Classifications } \\
\hline & Independent Tourist & Explorer & \multicolumn{3}{|l|}{ Escapist } \\
\hline Rank 1 & $162(48 \%)$ & $74(22 \%)$ & \multicolumn{3}{|l|}{$47(14 \%)$} \\
\hline Rank 2 & $71(21 \%)$ & $71(21 \%)$ & \multicolumn{3}{|l|}{$71(21 \%)$} \\
\hline Rank 3 & $27(8 \%)$ & $53(16 \%)$ & \multicolumn{3}{|l|}{$52(15 \%)$} \\
\hline Total & $260(77 \%)$ & $198(59 \%)$ & \multicolumn{3}{|l|}{$170(50 \%)$} \\
\hline \multicolumn{6}{|c|}{ Ranked Information Sources } \\
\hline & Travel Books/Guides & $\begin{array}{l}\text { Word of } \\
\text { Mouth }\end{array}$ & Television & Newspaper & Adverts. \\
\hline Rank $1^{\mathrm{b}}$ & $177(57.8 \%)$ & $62(18 \%)$ & $70(23 \%)$ & $47(13 \%)$ & $30(9 \%)$ \\
\hline Rank 2 & $103(33.7 \%)$ & $185(54 \%)$ & $70(23 \%)$ & $55(16 \%)$ & $47(13 \%)$ \\
\hline Rank 3 & $26(8.5 \%)$ & $73(21 \%)$ & $165(54 \%)$ & $197(58 \%)$ & $216(64 \%)$ \\
\hline Total & $306(90 \%)$ & $310(92 \%)$ & $305(90 \%)$ & $299(88 \%)$ & $293(87 \%)$ \\
\hline \multicolumn{6}{|c|}{ Comparative Ranks of Travel Books/Guides as a Tourism Information Source } \\
\hline & Domestic & \multicolumn{4}{|c|}{ International } \\
\hline Rank $1^{\mathrm{b}}$ & $93(53.1 \%)$ & \multicolumn{4}{|l|}{$84(64.1 \%)$} \\
\hline Rank 2 & $61(34.9 \%)$ & \multicolumn{4}{|l|}{$42(32.1 \%)$} \\
\hline Rank 3 & $21(12 \%)$ & \multicolumn{4}{|l|}{$5(3.8 \%)$} \\
\hline \multicolumn{6}{|c|}{ Comparative Ranks of Television as a Tourism Information Source } \\
\hline & Domestic & \multicolumn{4}{|c|}{ International } \\
\hline Rank $1^{\mathrm{b}}$ & $60(33.9 \%)$ & \multicolumn{4}{|l|}{$10(7.8 \%)$} \\
\hline Rank 2 & $48(27.1 \%)$ & \multicolumn{4}{|l|}{$22(17.2 \%)$} \\
\hline Rank 3 & $69(39 \%)$ & \multicolumn{4}{|l|}{$96(75 \%)$} \\
\hline
\end{tabular}

a The mean motivation score was calculated by averaging respondents' scores on an attitudinal Likert scale for several question, where 1 is strongly disagree and 6 is strongly agree.

b Information sources were ranked according to the scale: Rank 1 (very important), Rank 2 (slightly important) and Rank 3 (not important).

\section{Tourists' Appraisal of the ORIA}

Results from the replicated multidimensional unfolding solution analysis of the supergrid examining the disparities between each respondent for their evaluation of the 13 elements by the 20 constructs (Figure 2) created a two dimensional perceptual space $\left(r^{2}=0.72\right)$. The dimensional ranges of this space correspond to the aggregate personal constructs used to differentiate between the attractions.

As also can be seen from Figure 2, the 13 attractions are widely distributed across the area of 2-dimensional space, suggesting that the key evaluative constructs effectively describe the range of perceptions provided by the marketing materials. Within the 2-dimensional space, given that the distribution pattern corresponds to the disparities among elements as recorded in the repertory supergrid, distances 


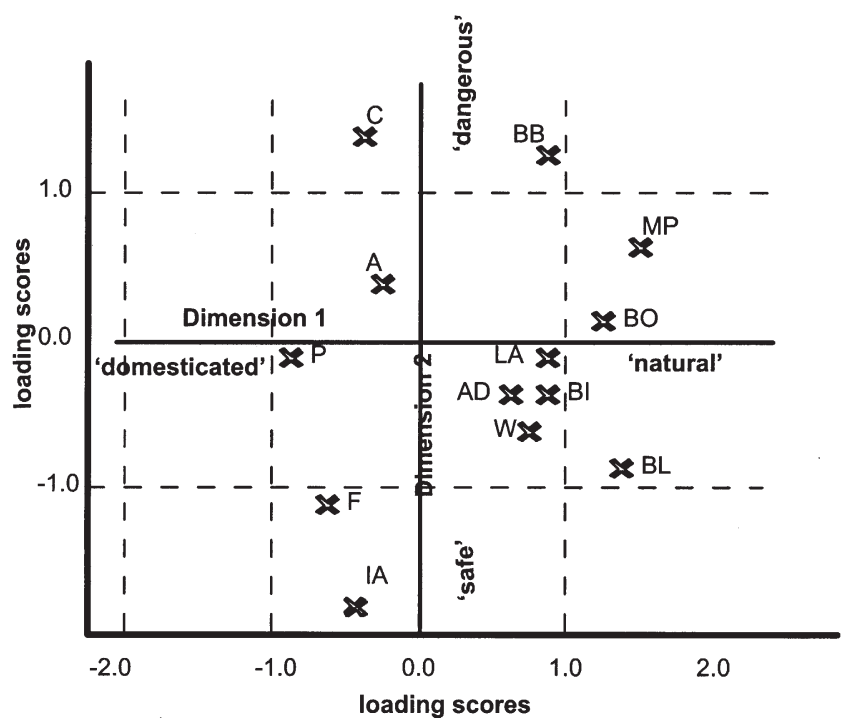

Key Elements: C Crocodile, A Aboriginal Australians, BB Bungle Bungles, MP Mitchell Plateau, BO Boab, LA Lake Argyle, AD Argyle Dam, Bl Billabong, W Wallaby, BL Birdlife, F Fishing, P Pastoralism, IA Irrigated Agriculture

Figure 2. The Repertory Grid for all Respondents

among the tourism attractions suggests that irrigated agriculture is perceived differently from the Argyle Dam, which is again perceived differently from both the Bungle Bungles and Aboriginal Australians. However, certain point elements are also shown to cluster. Therefore, their close positioning in perceptual space suggests that each forms part of a common cognitive set. For example, the Argyle Dam, Lake Argyle, billabong, and wallaby share the cognitive sets defined by the "natural" and "safety" dimensions. Other examples are the cognitive sets of "domesticated" and "safety", shared by both irrigated agriculture and fishing. The Mitchell Plateau and the Bungle Bungles share a common cognitive set of "natural" and "adventure".

Such results would appear to confirm arguments that nature's frame of reference has been expanded by marketing materials to incorporate the dam and its associated waterways, despite it being Australia's largest human-made structure. Such results are perhaps not surprising given that nature-based tourism drew on a reservoir of representations that since its construction have portrayed the dam as "natural". For example, at its opening ceremony, Premier Tonkin of Western Australia commented that the wall was as unobtrusive as a goanna on a rock and that "it will not be very long before it merges into the general landscape of the Carr-Boyd Ranges as if it were here quite naturally" (quoted in Arthur 1997:45). In reference to such comments, it is argued that European colonization simply brought the finishing touches to the landscape, as if on some eighth day of creation. The lake is naturally beautiful because it was always meant to be present 
(Arthur 1997:46). In contrast, the process of naturalization of human activities has not spilled over to affect the experience of the irrigation scheme's domesticated agricultural landscape.

Since the $80 \mathrm{~s}$, while the irrigated agricultural landscapes have been almost exclusively ignored by local tour operators, the spillways, reservoirs, diversion dams, and wetlands have been marketed as an integral part of the "wilderness experience". Including the lakes within nature's frame of reference has currency with tourism because extensive yet artificial water bodies (when constructed as wilderness and natural beauty) can be sold as a setting for sport, fishing, adventure, ecology, and romantic sunset tours. No such immediate justification existed for the irrigated landscapes.

To explore further whether these constructions of the ORIA are constant across the tourist population, additional analyses were conducted. The replicated multidimensional unfolding solution was utilized to ascertain whether patterns of discrimination existed across appraisals when differentiated by gender, holidaymaker classification, country of residence, and sources of information. As shown in Figure 3, the perceptual space according to gender is remarkably similar to the collective perceptual space. A strong resemblance exists between the distribution and clustering of point elements in the 2-dimensional perceptual space defined by cognitive sets. Parallel results were also seen in the resulting perceptual space when the population was differentiated by motivation and by holidaymaker classification. Regardless

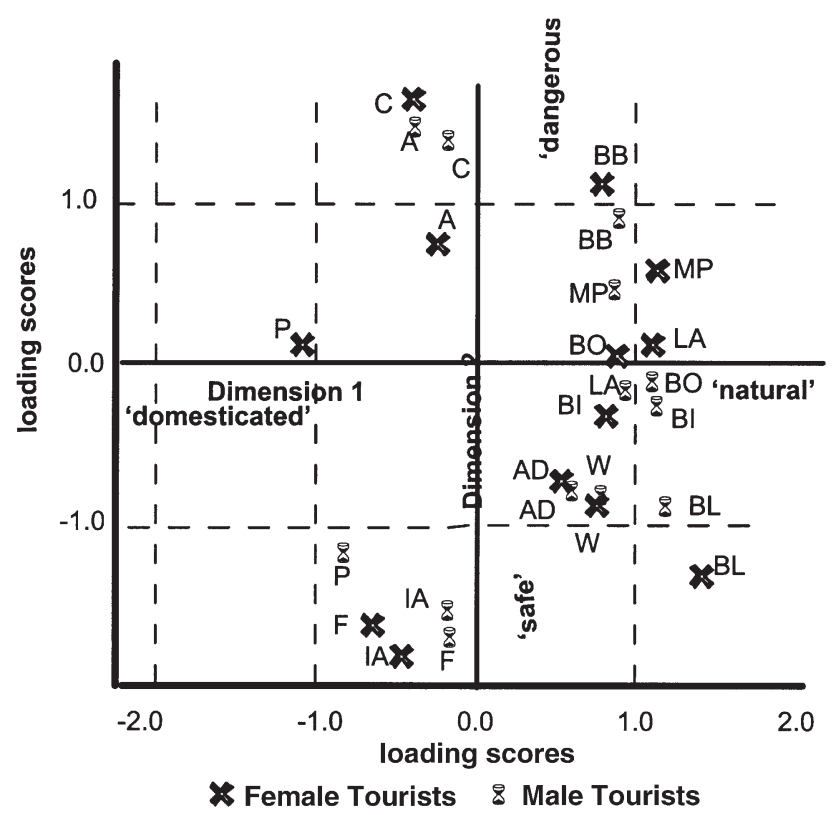

Key Elements: See figure 2

Figure 3. The Repertory Grids for Male and Female Respondents 
of the latter two and gender, the irrigated agriculture is appraised, along with fishing and pastoralism, as familiar and domesticated. In strong contrast, the appraisal of the Argyle Dam clusters with billabongs and rock wallabies, suggesting the dam has become naturalized.

However, as shown in Figure 4, there is a striking difference between the 2-dimensional perceptual spaces of international and domestic tourists. The former's pattern of point elements in perceptual space differed little from that of the total population. In contrast, domestic tourists were only able to perceive differences between crocodiles and the Bungle Bungles, appraised as both "dangerous" and "natural". The remaining attractions, including human activities, ORIA artifacts, landforms, flora and fauna, were appraised within cognitive sets as being both relatively "safe" and "natural".

Perhaps such apparent contradictory perceptions may have something to do with the relative familiarity of The Kimberley in the Australian collective imagining as the "last frontier". In Australian outback mythology, agricultural activities are quite legitimate. No cognitive difficulties arise from imagining outback landscapes as containing vast pastoral stations, homesteads, windmills, and drovers. Indeed their presence signifies the mythical transformation of wilderness into a "productive" landscape. Yet, even as outback mythology incorporates the pastoral industry, the wilderness remains ever present. This is a liminal space, where history is always just about to start. Pastoralism's connections with the land always remain tenuous.

A review of the guidebooks suggest that an awareness of this fragile

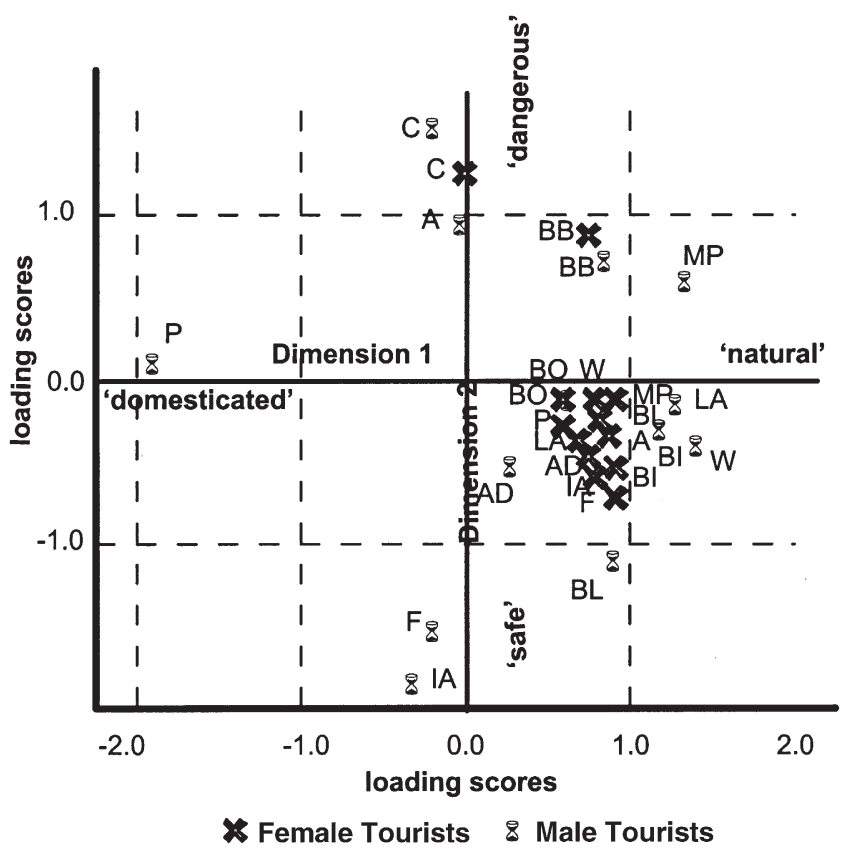

Figure 4. The Repertory Grid for Domestic and International Respondents 
connection with the land is generated in part through the wide circulation of the frontier myth in both Australian electronic and print media. Cited guides highlight the unique environment, the hazards of European pastoralism, agriculture and horticulture, as well as an itinerary of activities. To explore whether guidebooks constrained domestic tourists' appraisal, the second survey data was further analyzed. Figure 5 shows the results of a replicated multidimensional unfolding solution for domestic respondents who indicated guidebooks were a very important knowledge source. The distribution of point elements in the 2-dimensional perceptual space suggests that respondents who have read guidebooks do appraise the Kimberley differently from the total population. Irrigated agriculture and fishing are appraised as "natural", along with all other elements, confirming that the presence of certain human activities is still consistent with the frontier myth.

As shown in Table 2, television was also an important source of information, particularly among domestic tourists. A review of the television programs' content most commonly cited suggests that the Kimberley is regarded as the immersion in an unspoiled and, by implication, pristine nature. To explore whether these programs also constrained domestic tourists' landscape appraisal, a replicated multidimensional unfolding solution analysis was undertaken. As can be seen from Figure 5, those Australian respondents who watched the programs appraised all the elements within the confines of the frontier myth. The patterns of point elements within the 2-dimensional perceptual space suggest domestic tourists appraised all elements, with the exception of crocodiles, within the same cognitive set. The remaining elements, including

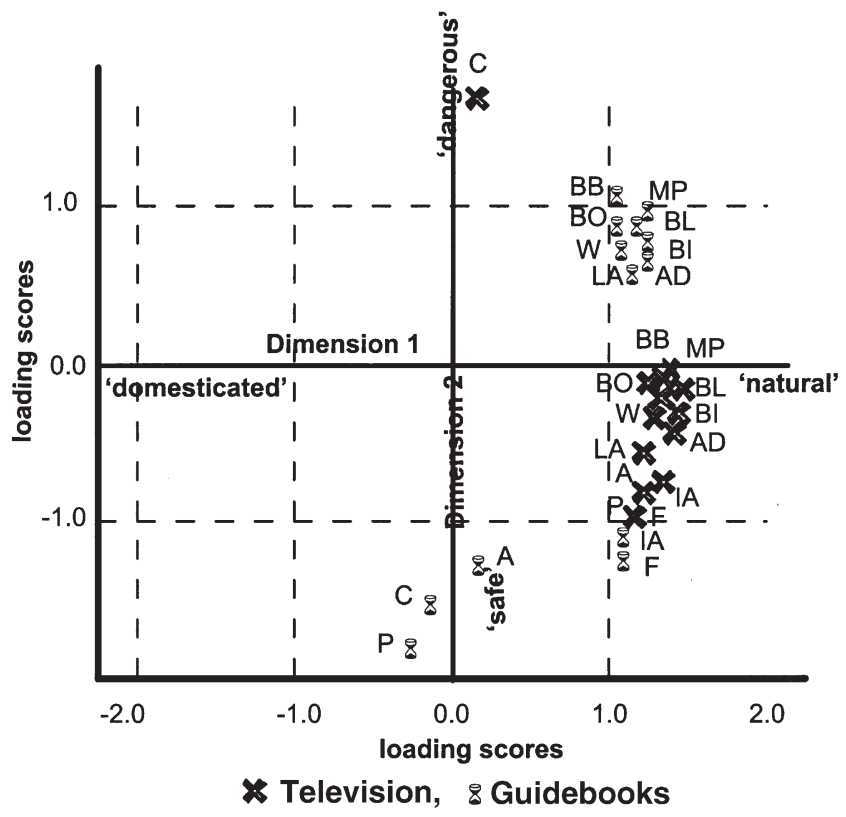

Figure 5. The Repertory Grids for Television and Guidebooks 
the Argyle Dam and irrigated agriculture, were appraised as not only more familiar, but also apparently "natural" attractions. Again, the frontier myth provides a potential explanation for this apparent naturalization of the dam and irrigated agriculture. Their presence at the frontier becomes essential in the mythical transformation of wilderness into a domesticated landscape.

\section{CONCLUSION}

The aim of this paper was to explore the role of tourism imagery in informing appraisals of the Kimberley. In particular the paper addressed the role of promotional imagery in overcoming the seeming contradictions presented by the ORIA in a region focused upon nature-based tourism. Within the western nature/human binary constructions, the irrigation scheme's agriculture, reservoirs, and dam lie outside nature's frame of reference. A potential threat to nature-based tourism is the presence of Australia's largest artifact. Personal construct theory provided an established methodology to examine the apparent contradictions between irrigation schemes and nature-based tourism activities. To this end, a four-stage examination was undertaken.

The repertory grid analysis identified a 2-dimensional perceptual space for the Kimberley, with the two aggregate personal constructs influencing perceptions within this space labeled "domesticated" versus "natural" and "safe" versus "dangerous". Repertory grid analyses suggest that regardless of how respondents are categorized, they perceive both the Argyle Dam and Lake Argyle in a similar fashion to billabongs, wallabies, and bird-life, as part of the "natural" landscape. Apparently, the tourism industry has successfully naturalized the dam and reservoir, dissolving the human/nature binary. This confirms Dann's (1996) argument regarding the crucial role of in guiding viewers to a particular understanding of their surroundings. In answer to Selwyn's (1996) question, it would appear that in this case tourists are "suckers for the surfaces of the tourism brochure". The imagery texts would appear to play an integral role in closing different social constructions of the ORIA, particularly those anti-dam portrayals offered by conservationists, pastoralists, and indigenous Australians who witnessed the extensive drowning of country (Bulla, in Shaw 1986:1712). Appraised as natural, both the dam and reservoir help to sustain the symbiotic relationship established between tourism and agriculture constructed by the pro-dam economic and political literature. Therefore, the water systems that will supply Ord Stage Two pose no threat to tourism.

The irrigated agriculture, however, is experienced quite differently. Overall, tourists appraise the irrigated agriculture in terms of a human landscape, familiar and mundane. In this instance, the human/nature binary actively defines the boundaries of nature-based tourism. The results suggest that when understood in terms of a familiar human activity, expansion of the irrigated agriculture area may indeed be contrary to the industry's interests. The threat does not come from diminishing sites currently visited. The proposed irrigated agriculture is on 
alluvial plains with no present attractions. However, tourists will have to travel through this extensive irrigated agricultural system as part of their journey through Northwest Australia or to visit specific attractions (Figure 1). The potential threat of extending the area of irrigationfed agriculture is one of geographical imagination. How can tourists reconcile a coherent place-image for a region in which agriculture, which they understand as mundane and domesticated, coincides with a nature-based tourism industry trading on experiences of "natural" and "wild places"?

Yet, how the irrigated areas are perceived is complicated by quite distinct patterns of component scores between domestic and international tourists. The latter retained a similar perceptual space to the overall appraisal, resulting in conflicting cognition of agriculture and nature-based tourism. However, with the exception of landscapes featuring the Bungle Bungles and crocodiles, domestic tourists' configuration of the perceptual space demonstrated an inability to differentiate the region's attractions from one another. All other attractions, including the irrigated agriculture, were experienced as "natural". Such apparent contradictions may themselves be explained within the context of the familiarity among Australians of the frontier myth, perpetuated by the industry in television programs and guide books. Indeed, the characteristic of assigning all sites to the "natural" dimension is demonstrated in the component score patterns of those respondents who acknowledged the importance of television as an information source. The Kimberley, according to the frontier myth's linear narrative, is a marginal location outside of the ambit of human society. Instantly, the whole location becomes imagined as wild and empty, a remnant of primal nature. Agricultural practices are understood as an integral, yet tenuous part of the uniquely Australian outback lifestyle.

Tourism is sustained by experiences. For the Kimberley, the challenge presented by the proposed Ord Stage Two is the intensifying contradictory appraisals of irrigated agricultural landscapes on the one hand, and part of the Australian frontier myth, on the other. This contradiction has particular resonance for those international and domestic tourists least familiar with the Australian frontier myth. For them the irrigated landscape was understood as both domesticated and safe; further extension of irrigated agriculture may only contradict their experience of an escape to a wild place. Marketing can augment such potentially contradictory experiences. In the Kimberley, the government and the tourism industry have successfully portrayed the landscapes of ORIA as natural, even if they are artificial. Clearly, the Western Australian and Northern Territory governments, in their enthusiasm to proceed with Ord Stage Two and to extend irrigated agricultural landscapes, must also consider a regional tourism marketing strategy. Increased exposure to the frontier myth may help assure that future tourists, particularly from overseas, will experience the changing landscapes of the ORIA as a wild and natural place. However, such a colonizing myth while making agriculture unproblematic, sustains notions of Australia as terra nullius, casts Aboriginals in the essentialistic gaze of romantic primitivism and promotes environmental 
determinism as an explanation of national identity. The heroic and primitive simplicity of the frontier myth may sustain a flow of tourism revenue to the region. However, fashioning the Kimberley to meet this demand maintains representations of Australia to both national and overseas audiences through the cracked mirror of the Anglo-Celtic gaze. A

Acknowledgements—Funding for this project was from the Environmental Research Institute, University of Wollongong. The authors are indebted to the helpful and constructive comments provided by Murray Wilson.

\section{REFERENCES}

Arthur, J.

1997 An Unobtrusive Goanna. In Tracking Knowledge in North Australian Landscapes, D. Rose and A. Clarke, eds., pp. 37-49. Darwin: The Australian National University Northern Australia Research Unit.

Chokor, B.

1991 Triad Comparison Judgments and Place Significance. Area 23:136-149.

Daly, M., A. Dehne, D. Leffman, and C. Scott

1995 Australia, The Rough Guide. London: Penguin Rough Guides.

Dann, G.

1996 The Language of Tourism: A Sociolinguistic Perspective. Wallingford: $\mathrm{CAB}$ International.

Durack, M.

1986 [1959] Kings in Grass Castles. Condell Park: Corgi Books, Transworld Publishers.

Easterby-Smith, M.

1981 The Design, Analysis and Interpretation of Repertory Grids. In Recent Advances in Personal Construct Technology, M. Shaw, ed., pp. 9-30. London: Academic Press.

Fransella, F., and D. Banniester

1977 A Manual for Repertory Grid Technique. London: Academic Press.

Hassall

1993 The Ord River Project Past, Present and Future: An Economic Evaluation. Stage 1 Prepared by Hassal and Associates P/L for Kimberley Water Resources Development Office. Perth: Hassall and Associates.

Harrison, J., and P. Sarre

1976 Personal Construct Theory, the Repertory Grid, and Environmental Cognition. In Environmental Knowing, G. Moore and R. Golledge, eds., pp. 375384. Stroudsburg PA: Hutchinson and Ross.

Head, L.

1994 Aborigines and Pastoralism in North-Western Australia: Historical and Contemporary Perspectives on Multiple use of the Rangelands. Rangelands Journal 16:167-183.

1999 The Northern Myth Revisited? Aborigines, Environment and Agriculture in the Ord River Irrigation Scheme, Stages One and Two. Australian Geographical Studies 30:141-158.

Kalekin-Fishman, D., and B. Walker

1996 The Construction of Group Realities: Culture, Society and Personal Construct Theory. Malabar: Krieger.

Kapferer, B.

1988 Legends of People Myths of State. Violence, Intolerance and Political Culture in Sri Lanka and Australia. Washington DC: Smithsonian Institute Press.

Kelly, G.

1955 The Psychology of Personal Constructs. New York: Norton.

Kinhill P.

2000 Environmental Review and Management Programme. Draft Environmen- 
tal Impact Statement. Proposed Development of the M2 Area. Ord River Irrigation Area Stage 2. Prepared by Kinhill Pty Ltd for Westfarmers Sugar Company Pty Ltd, Marubeni Corporation and Water Corporation of Western Australia. Perth: Kinhill Pty Ltd.

Langton, M.

1994 Valuing Cultures: Recognizing Indigenous Cultures as a Value Part of Australian Heritage. Council for Aboriginal Reconciliation. Canberra: Australian Government Publication Service.

Markwick, M.

2001 Postcards from Malta. Image, Consumption, Context. Annals of Tourism Research 28:417-438.

McClintock, A.

1995 Imperial Leather. Race, Gender and Sexuality in the Colonial Contest. New York: Routledge.

McGonigal, D.

1990 The Kimberley. Terry Hills NSW: Australian Geographic Pty.

McGregor, A.

2000 Dynamic Texts and Tourist Gaze: Death, Bones and Buffalo. Annals of Tourism Research 27:27-50.

McGregor, G.

1994 EcCentric Visions. Re-Constructing Australia. New York: Wilfred Lauruer University Press.

Macnaghten, P., and J. Urry

1998 Contested Natures. London. Thousand Oaks CA: Sage.

Moon, R., and V. Moon

1989 The Kimberley an Adventurer's Guide. Chelsea: Kakirra Adventure Publications.

1997 The Kimberley an Adventurer's Guide. Chelsea: Kakirra Adventure Publications.

Naralup Associates

1996 Ord Irrigation Project: Population Planning Study. Perth: Naralup Associates.

Pearce, $\mathrm{P}$.

1982 The Social Psychology of Tourist Behaviour. Oxford: Pergamon.

Pearce, P., and M. Caltabiano

1983 Inferring Travel Motivation from Travelers' Experiences. Journal of Travel Research 22:16-20.

Rojek, C., and J. Urry

1997 Touring Cultures: Transformations of Travel and Theory. London: Routledge.

Rose, D.

1991 Hidden Histories: Black Stories from Victoria River Down, Humbert River and Wave Hill Stations. Canberra: Aboriginal Studies Press.

1997 The Year Zero and the North Australian Frontier. In Tracking Knowledge in North Australian Landscapes, D. Rose and A. Clarke, eds., pp. 19-36. Darwin: The Australian National University Northern Australia Research Unit.

Sayer, A.

1992 Method in Social Science: A Realist Approach. London: Hutchinson.

Selwyn, T.

1996 The Tourist Image: Myths and Myth Making in Tourism. Chichester: Wiley, pp. 1-32.

Senior, C.

1987 Tourism and Aboriginal heritage with Particular Reference to the Kimberley. Perth: Western Australian Museum.

Shaw, B.

1986 Countrymen: The Life Histories of Four Aboriginal Men. Canberra: Australian Institute of Aboriginal Studies. Smith, D.

1990 Publisher's Introduction. In The Kimberley, D. McGonigel, ed., pp. 3-4. Terry Hills NSW: Australian Geographic Pty. 
Squire, S.

1994 Accounting for Cultural Meanings: The Interface between Geography and Tourism Studies Re-Examined. Progress in Human Geography 18:1-16.

Turner, F.

1920 The Frontier in American History. New York: Henry Holt.

Urry, J.

1990 The Tourist Gaze: Leisure and Travel in Contemporary Societies. London: Sage.

Waitt, G.

1997 Selling Paradise and Adventure: Representations of Landscape in the Tourist Advertising of Australia. Australian Geographical Studies 35(1):47-60.

Walmsley, D., and M. Young

1998 Evaluative Images and Tourism: The Use of Personal Constructs to Describe the Structure of Destination Images. Journal of Travel Research 36(3):65-69.

Ward, R.

1958 The Australian Legend. Melbourne: Oxford University Press.

Ward, L., and J. Russel

1981 Cognitive Set and Perception of Place. Environment and Behaviour 13:610-632.

Warren, B.

1990 Psychoanalysis and Personal Construct Theory: An Exploration. Journal of Psychology 124:449-463.

WATC

1996 Tourism Research Brief on Kimberley 1995 and 1996. Perth: Western Australia Tourist Commission.

1999 Discover Western Australia. Ringwood: Penguin Books Australia.

WATC and KDC

1998 East Kimberley: Accommodation Needs Analysis 1997-2005. Report prepared by Focused Management for Western Australian Tourism Commission and Kimberley Development Commission. Claremont WA: Focused Management.

Young, M.

1999 The Social Construction of Tourist Places. Australian Geographer 30:373-390.

Yiannakis, A., and H. Gibson

1992 Roles Tourist Play. Annals of Tourism Research 19:287-303.

Zube, E., D. Pitt, and T. Anderson

1975 Perception and Prediction of Scenic Resource Values of the Northeast. In Landscape Assessment: Values, Perceptions and Resources, E. Zube, R. Brush and J. Fabos, eds., pp. 151-169. Stroudsburg PA: Hutchinson and Ross.

Submitted 27 March 2001. Resubmitted 30 May 2002. Resubmitted 17 June 2002. Accepted 25 June 2002. Refereed anonymously. Coordinating Editor: Bob McKercher 